\title{
Medical student attitudes towards older people: a critical review of quantitative measures
}

\author{
Mark A. G. Wilson ${ }^{1 *}$, Susan Kurrle ${ }^{2}$ and lan Wilson ${ }^{3}$
}

\begin{abstract}
Objectives: Further research into medical student attitudes towards older people is important, and requires accurate and detailed evaluative methodology. The two objectives for this paper are: (1) From the literature, to critically review instruments of measure for medical student attitudes towards older people, and (2) To recommend the most appropriate quantitative instrument for future research into medical student attitudes towards older people.

Results: A SCOPUS and Ovid cross search was performed using the keywords Attitude and medical student and aged or older or elderly. This search was supplemented by manual searching, guided by citations in articles identified by the initial literature search, using the SCOPUS and PubMed databases. International studies quantifying medical student attitudes have demonstrated neutral to positive attitudes towards older people, using various instruments. The most commonly used instruments are the Ageing Semantic Differential (ASD) and the University of California Los Angeles Geriatric Attitudes Scale, with several other measures occasionally used. All instruments used to date have inherent weaknesses. A reliable and valid instrument with which to quantify modern medical student attitudes towards older people has not yet been developed. Adaptation of the ASD for contemporary usage is recommended.
\end{abstract}

Keywords: Instrument, Quantify, Medical student, Attitudes, Aged persons

\section{Introduction}

Medical student attitudes towards older people in the community are important to understand and quantify. Ageist attitudes, ubiquitous in the healthcare sector, may influence medical practice [1]. There are many examples of ageism in the literature, including the reticence of some primary care physicians to take on the care of older people [2], provision of less information to older people by doctors [3], cardiologists offering a narrower range of options to older patients [4], and specialists offering less aggressive treatment to older women with breast cancer [5]. To ameliorate such ageism, fostering development of positive attitudes towards older people during medical training must be a fundamental outcome of medical curricula.

*Correspondence: markw@uow.edu.au

1 Graduate Medicine, School of Medicine, University of Wollongong, PO Box 1782, Bowral, NSW 2576, Australia

Full list of author information is available at the end of the article
Fixed medical student views about older people have been studied for over 50 years. The first longitudinal study investigating attitudes recently provided evidence that student attitudes towards older people decline throughout medical school [6]. As attitudes are complex and multi-dimensional, both qualitative and quantitative research are required to provide more comprehensive understanding. One of the greatest challenges in understanding student attitudes has been the plethora of instruments used in their measurement, each with particular deficiencies. The aims of this paper are to critically review the instruments which have been utilised to quantify medical student attitudes, and to identify the optimal instrument type for future medical education research.

\section{Main text \\ Method}

On 18th March 2016, 171 articles were identified utilising the following keywords: Attitudes AND medical student AND older OR old OR elderly in the database SCOPUS, 
and by manual searching directed by article citations, using SCOPUS and PubMed. An additional 371 articles were found by an Ovid Cross Search using the same search parameters. During March and April 2016, from a total of 542 articles identified by the search, 299 were found to be relevant, after eliminating those not in English (29), duplicated (147), or found to be unrelated to the area of interest by screening title, abstract and text (76).

An additional Ovid Cross Search was performed using the same search terms on May 5 2017, identifying 9 new articles since the original search. A total of 308 peerreviewed journal articles were thus reviewed to inform this paper (see Fig. 1).

\section{Results}

Three systematic reviews of health professional, including medical student, attitudes towards older adults were identified from the literature [7-9]. In addition to these studies, several other studies of medical student attitudes were identified by this review. Most research has quantified the effect of geriatric medical curriculum innovation on medical student attitudes, and has either shown neutral or positive effect. Some studies simply sought to describe the attitudes of a cohort of medical students. Thirty- one relevant studies, including instruments used to measure attitudes, are summarised in Table 1.

\section{A description and comparison of the instruments used for measurement of medical student attitudes towards older people}

The Ageing Semantic Differential (ASD) The most widely used instrument in published studies of medical student attitudes towards older people has been the ASD. The construct of semantic differential was first adapted to study social stereotypes in 1946 [41], introducing the potential for this instrument type to test multiple dimensions of attitudes [42]. The ASD directs respondents to indicate which of thirty-two polar adjectives best describes their attitude to an older person across a seven step scale. The subject is asked to indicate the point on the scale which represents the direction and intensity of his or her judgement between each pair of polar opposite adjectives. Three major dimensions were identified by factor analysis: instrumental-ineffective, autonomous-dependent, and personal acceptability-unacceptability [43].

The semantic differential (SD) approach to quantifying medical student attitudes has several strengths: SD eliminates the problem of statements within instruments, which may capture beliefs rather than attitudes, a potential flaw of many instruments [44]. The ASD more specifically quantifies attitudes, whereas other instruments such as the Kogan Attitude Toward Old Persons Scale [45] or the Palmore scale [46] confound attitudes with knowledge. SD requires relatively short survey times for measuring complex concepts [47], and has reported superior reliability and validity over Likert-based or Stapel scales [48].

While the ASD is widely used, there are three main areas of potential weakness:

1. Many adjectives employed by the ASD are outdated, with polar adjectives derived from surveys done in the United States of America in the 1950s [43]. Selection criteria of words for the scale are unclear. The pilot study tested the instrument on non-medical undergraduates at the University of Missouri. Some argue that vague or unfamiliar adjectives may result in students choosing more neutral responses [33].

2. The original work did not evaluate young people's attitudes towards older women. The original factor analysis of the ASD asked respondents to use the ASD to evaluate three different age groups of men, the oldest attitudinal object group consisting of men 70 to 85 years of age [43]. Sexism has no place today in the accurate measurement of attitudes towards older people.

3. There is a question of whether the ASD has validity, and whether it measures what it was intended to measure. The factor structure of the original ASD has been debated $[49,50]$, with some favouring a four factor structure as a better fit to the data [44].

Polizzi's refined ageing semantic differential The original ASD was refined in 2003, converting the instrument to 24 adjectival pairs using only one factor, the evaluative factor [50]. Polizzi's refined ASD has been criticised as a having poor fit using structural equation modelling [51]. A recent US study evaluating the validity of the refined ASD concluded that the refined ASD lacked validity, and was a unidimensional instrument. On the basis of qualitative data from this study, a four factor instrument was postulated, with experience the new factor [19].

The University of California Los Angeles Geriatric Attitude Scale (UCLA-GAS) and modified versions Another widely used instrument to measure attitudes of medical students towards older people is the UCLA-GAS. The UCLA-GAS is a 14 item survey using Likert-scale responses indicating whether the respondent agrees or disagrees with the statement. Cronbach's alpha in the original work was 0.76 , with good construct validity [52]. However, the UCLA-GAS makes use of five positive and nine negative statements about older patients, exposing the method to criticisms including the tool measures beliefs rather than attitudes [44], and is unbalanced or may have other problems with construct validity [53]. 
Ovid Cross Search March $18^{\text {th }} 2016$

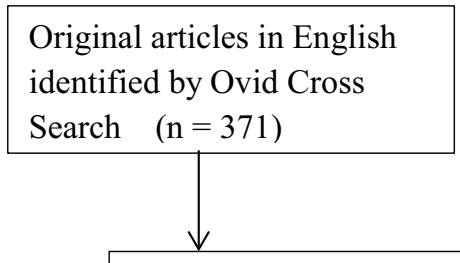

Scopus Search March $18^{\text {th }} 2016$

Original articles in English identified using SCOPUS search and additional manual searching using PubMed $\quad(\mathrm{n}=171)$
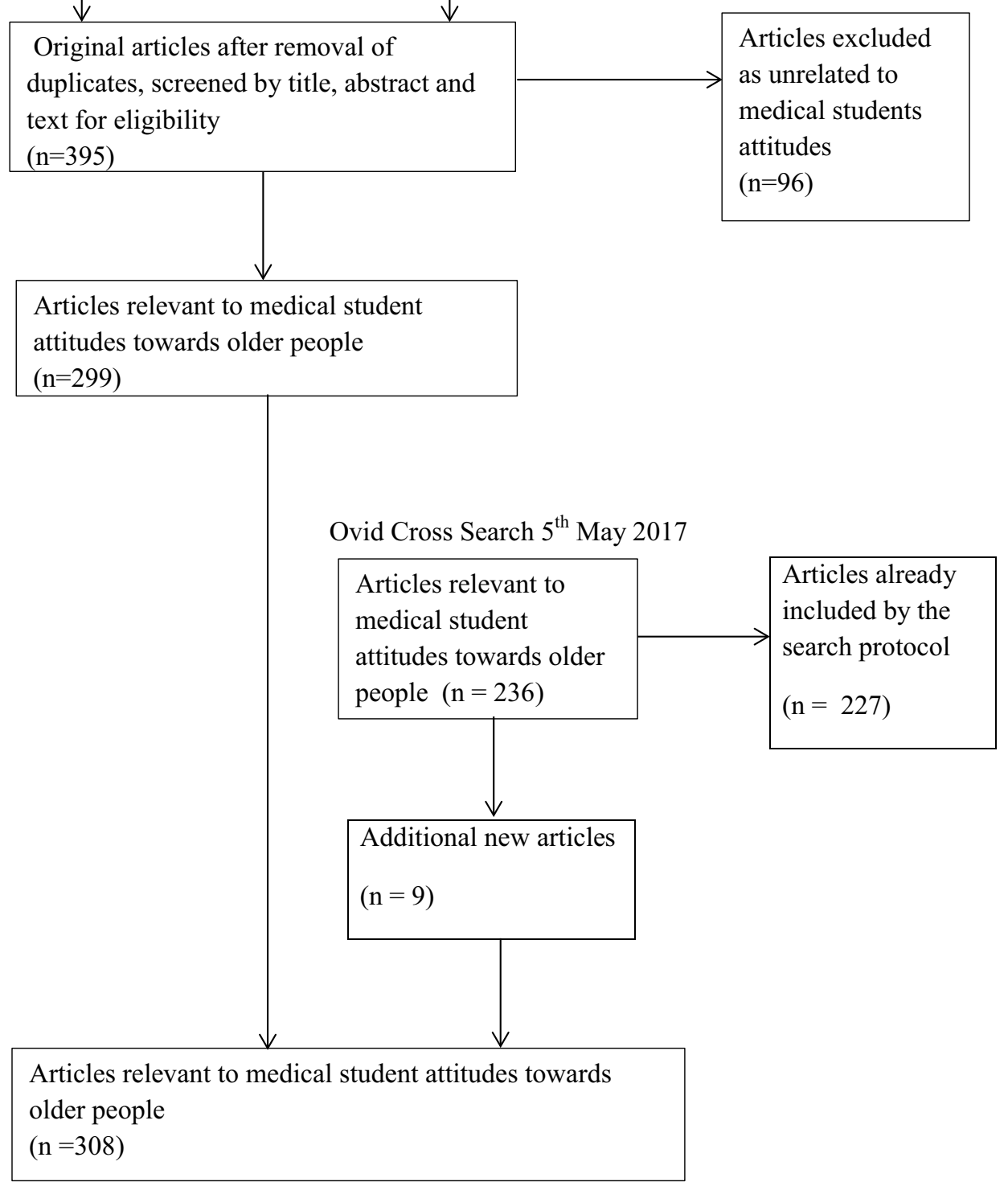

Fig. 1 Search strategy for literature review of attitudes of medical students towards older people. A total of 308 peer-reviewed journal articles were reviewed to inform this paper. In March 2016, 542 articles were identified utilising the keywords attitudes and medical student and older or old or elderly in the database SCOPUS, by manual searching directed by article citations, using SCOPUS and PubMed, and by an Ovid Cross Search using the same search parameters. 299 articles were found to be relevant, after eliminating those not in English, duplicated, or unrelated to the area of interest by screening title, abstract and text. An additional Ovid Cross Search, performed using the same search terms in May 2017, identified 9 new articles since the original search

Some authors have expressed a view that the UCLAGAS by its very structure may inadvertently support the messages of ageism [16]. Initially developed for medical residents in 1998 [52], the UCLA-GAS has been used to investigate medical student attitudes. In US studies, the internal reliability for the UCLA-GAS or modified version 


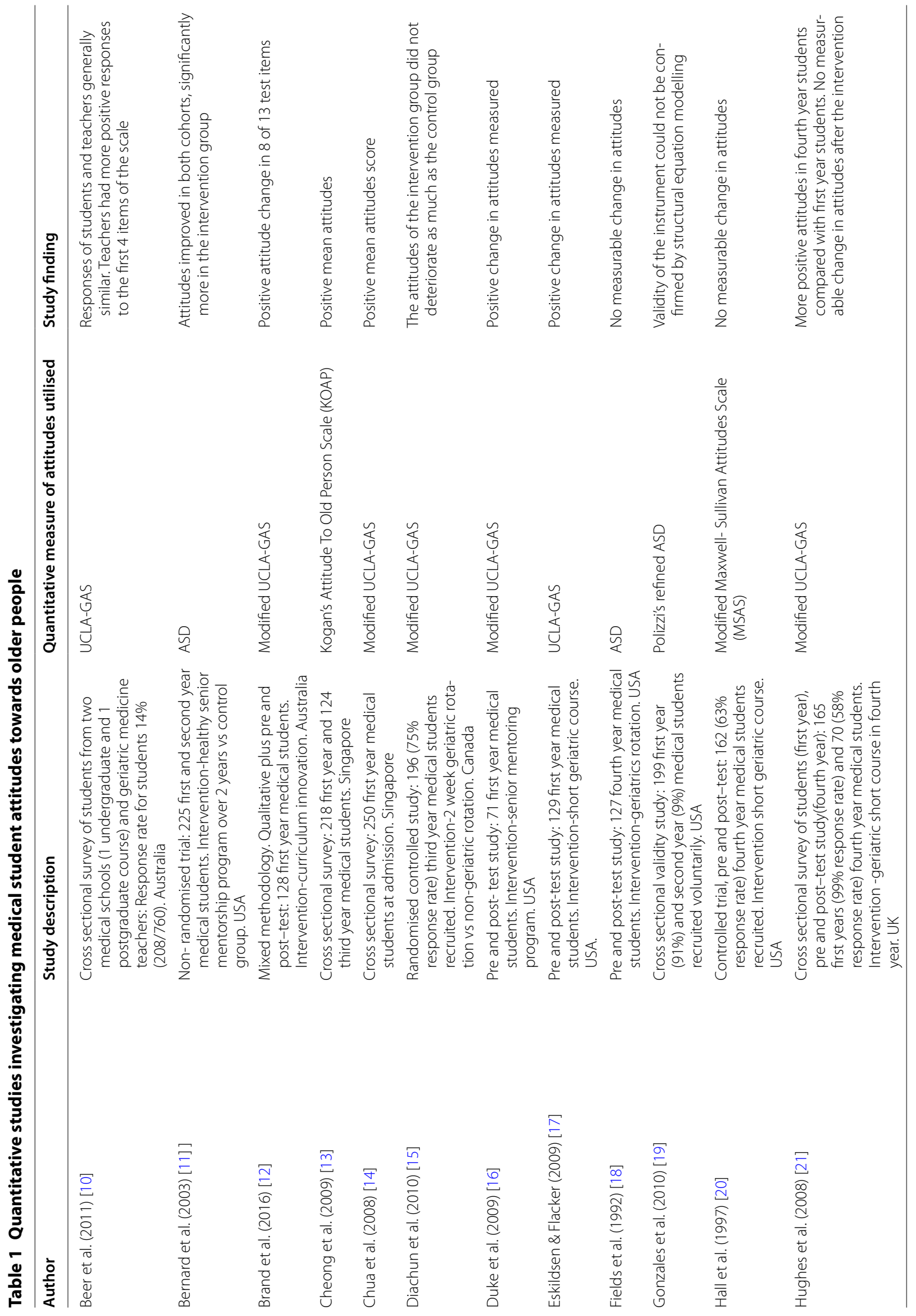




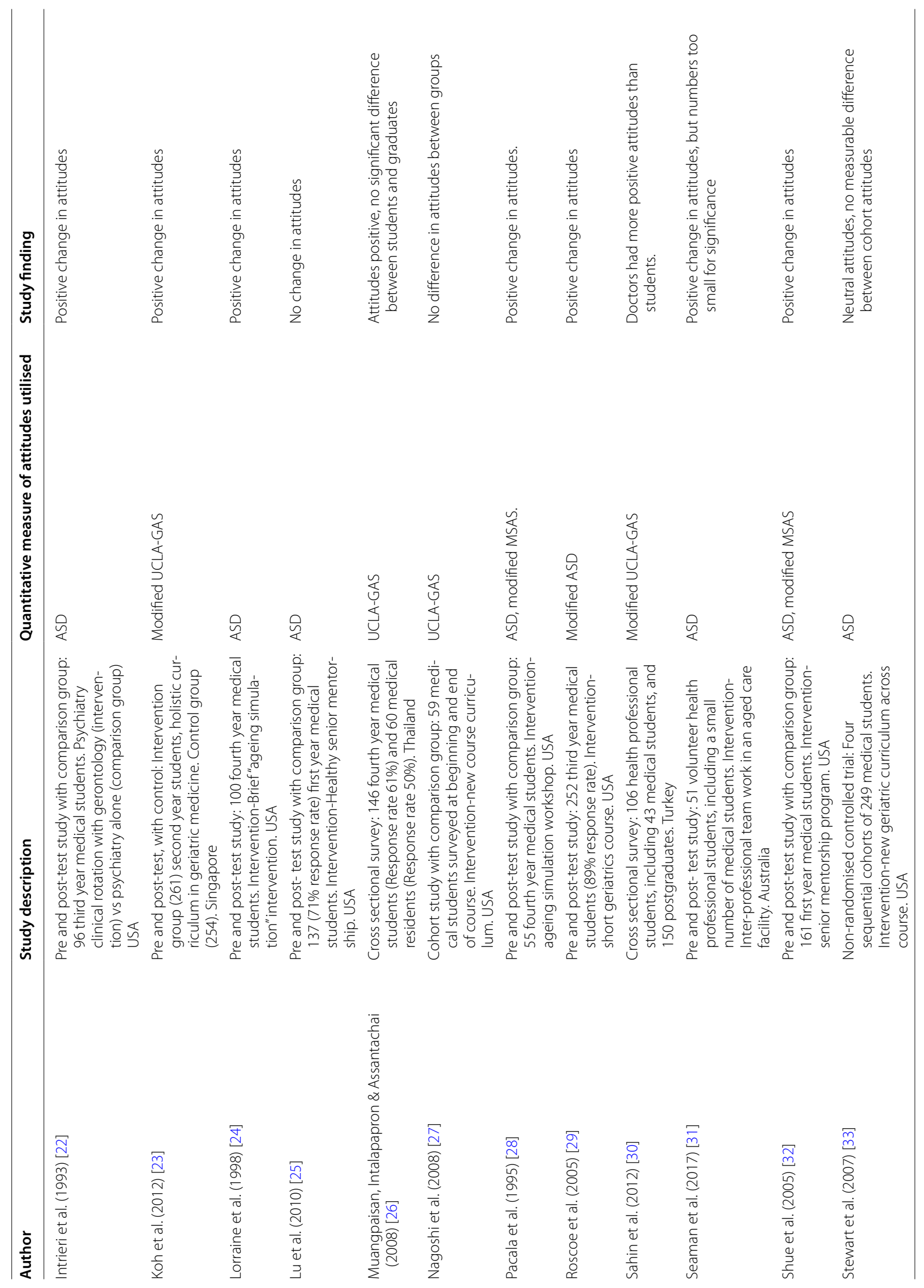




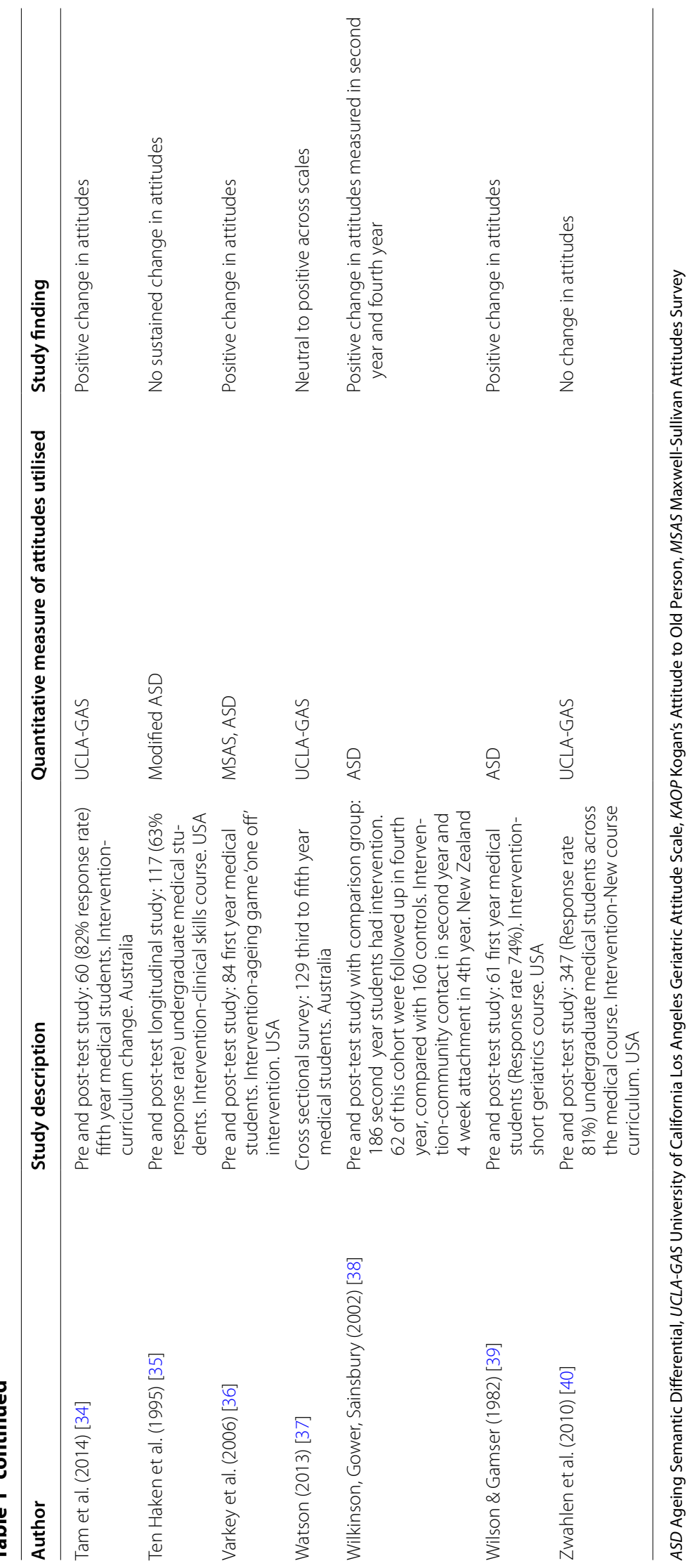


has been sub-optimal (Cronbach's alpha 0.69) in studies outside UCLA [53-55].

Despite concerns regarding the reliability and validity in measuring medical student attitudes in the US, the UCLA-GAS has been used internationally, often with modification. Three items were modified in the Singapore UCLA-GAS, with Cronbach's alpha 0.73 when administered to first year medical students [14], but alpha of $0.61-0.69$ in a subsequent Singapore study [23]. Turkish investigators studied medical student attitudes using a literally translated UCLA-GAS instrument. Cronbach's alpha was 0.67 . An attempt was made to show validity by comparing student responses on a local unvalidated scale of elderly discrimination attitudes [30]. The authors of a study comparing attitudes of medical students and residents towards older people in Thailand used a modified UCLA-GAS, finding no significant difference between student and resident attitudes, not describing reliability [26]. One Australian study of fourth year medical students and their teachers provides evidence of internal reliability (Cronbach's alpha 0.78) for the UCLA-GAS and some evidence of content validity, with geriatric medicine teachers having more positive attitudes scores than their students [10].

The Maxwell-Sullivan Attitudes Survey (MSAS) Another instrument occasionally used to quantify attitudes towards older patients is the MSAS [56], developed for use with trainees in family medicine [52]. It is a 28 item survey within five scales, in part attitudinal, but also concerning educational preparedness to manage older patients. Significant concerns about the reliability and validity of the MSAS $[33,52]$ limit the scale's utility in medical student attitudes research.

Kogan's Attitude to Old Person Scale As indicated earlier, this scale confounds knowledge and beliefs with attitudes, and has seldom been used to measure medical student attitudes. There are flaws in the structure of this scale, making its psychometric utility questionable [51].

\section{Other quantitative instruments for measuring medical student attitudes to older people}

Fraboni's Scale on Ageism Fraboni's Scale on Ageism (FSA), developed from studies of Canadian high school and college students, and workers, consists of 29 statements which evaluate attitudes towards older people [57]. In studies of age bias in university students, the FSA has some evidence of reliability and validity [58]. The scale has scarcely been used to investigate medical professional attitudes. Used in one Australian study of hospital doctors' attitudes, results indicated neutral to positive mean attitudes [59]. Validity and reliability of the scale for either medical graduate or student research is unknown.

Carolina opinions on care of older adults A more recently developed instrument, the Carolina Opinions on Care of Older Adults, was developed in view of questions in relation to the reliability and generalizability of other instruments [60]. While promising in a North Carolina context, there is no further published evidence of repeatability and reliability for this instrument.

Implicit association test Another interesting area of research with regard to student attitudes towards older people are implicit attitude measures. The Implicit Association Test involves a rapid sorting task between two contrasting categories, comparing response latencies to stimuli, for example adjectives or faces of younger versus older people [61]. Whilst not described in medical student research, a study of psychology students demonstrated positive explicit attitudes but neutral implicit attitudes toward older people [61]. The authors postulate that respondents may avoid a socially undesirable response to explicit attitudes instruments.

\section{Discussion}

Currently no reliable and well validated instrument is available for use in quantitative research into medical student attitudes towards older people. On reviewing the literature where instruments have been used to quantify medical student attitudes towards older people, the instrument type with the most positive attributes is semantic differential (SD). A SD has the potential to reliably measure complex attitudes in a short space of time [47], which is important when surveying busy medical students. A well- constructed SD instrument should be more specific in measurement of student attitudes than explicit instruments utilising statements that may confound student attitudes with beliefs and/or knowledge about older people [44, 51]. Respondents' evaluative responses are less likely to be inhibited by an SD as compared with more explicit instruments [61]. Within a semantic differential, several dimensions of medical student attitudes may be evaluated, potentially providing greater insights.

Although the ASD has been extensively used for research of medical student attitudes toward older people, important flaws in this tool require addressing. The adjectives in a refined ASD instrument should reflect contemporary language, the evaluation should be of an older male or female person, and the newly refined instrument should undergo appropriate tests for reliability and validity in the context where it is utilised. A 
previous attempt made by Polizzi to refine the ASD [50], has proven to be inadequate $[19,51]$.

Medical student attitudes towards older people must be accurately quantified and understood for medical educators to effectively develop curricula in geriatric medicine which foster positive attitudes to older people as a core graduate outcome. We suggest that a properly validated modified ASD instrument be developed, using contemporary language and designed to measure multiple dimensions of medical student attitudes towards older people. Future quantitative studies should be complemented by qualitative data to more fully inform educators in geriatric medicine.

\section{Limitations}

It is possible that a systematic review may have identified additional instruments or evidence to inform this critical review. Attitudes are complex, multi-dimensional and challenging to accurately quantify in medical education research.

\author{
Abbreviations \\ ASD: Ageing Semantic Differential; UCLA-GAS: University of California Los \\ Angeles Geriatric Attitude Scale; KAOP: Kogan's Attitude to Old Person; SD: \\ semantic differential; MSAS: Maxwell-Sullivan Attitudes Survey; FSA: Fraboni's \\ Scale on Ageism.
}

\section{Authors' contributions}

MW conceived the study and conducted the literature review. MW contributed approximately $60 \%$ of the manuscript drafting, with approximately $20 \%$ input from SK and 20\% input from IW. MW, SK, and IW jointly approved the final manuscript. All authors read and approved the final manuscript.

\section{Author details}

${ }^{1}$ Graduate Medicine, School of Medicine, University of Wollongong, PO Box 1782, Bowral, NSW 2576, Australia. ${ }^{2}$ Health Care of Older People, Faculty of Medicine, University of Sydney, Hornsby Ku-ring-gai Health Service, Hornsby, NSW 2077, Australia. ${ }^{3}$ Learning and Teaching, School of Medicine, Faculty of Science, Medicine and Health, University of Wollongong, Building 28 Rm 115, Wollongong, NSW 2522, Australia.

\section{Acknowledgements}

Not applicable.

\section{Competing interests}

The authors declare that they have no competing interests.

Availability of data and materials

Not applicable.

\section{Consent for publication}

Not applicable.

\section{Ethics approval and consent to participate}

Not applicable.

\section{Funding}

This paper did not require any funding support.

\section{Publisher's Note}

Springer Nature remains neutral with regard to jurisdictional claims in published maps and institutional affiliations.
Received: 12 November 2017 Accepted: 17 January 2018

Published online: 24 January 2018

\section{References}

1. Nussbaum JF, Pitts MJ, Huber FN, RaupKrieger JL, Ohs JE. Ageism and ageist language across the life span: intimate relationships and nonintimate interactions. J Soc Issues. 2005;61(2):287-305.

2. Damiano PC. Factors affecting primary care physician participation in medicare. Med Care. 1997;35(10):1008-19.

3. Adler SR. Patient assertiveness in ethnically diverse older women with breast cancer: challenging stereotypes of the elderly. J Aging Stud. 1998;12(4):331-50.

4. Bowling A. Ageism in cardiology. Br Med J. 1999;319(7221):1353-5.

5. Protière C, Viens P, Rousseau F, Moatti JP. Prescribers' attitudes toward elderly breast cancer patients. Discrimination or empathy? Crit Rev Oncol Hematol. 2010;75(2):138-50.

6. De Biasio JC, Parkas V, Soriano RP. Longitudinal assessment of medical student attitudes toward older people. Med Teach. 2016;38(8):823-8.

7. Samra R, Griffiths A, Cox T, Conroy S, Gordon A, Gladman JRF. Medical students' and doctors' attitudes towards older patients and their care in hospital settings: a conceptualisation. Age Ageing. 2015;44(5):776-83.

8. Liu YE, While AE, Norman IJ, Ye W. Health professionals' attitudes toward older people and older patients: a systematic review. J Interprof Care. 2012;26(5):397-409.

9. Tullo ES, Spencer J, Allan L. Systematic review: helping the young to understand the old. Teaching interventions in geriatrics to improve the knowledge, skills, and attitudes of undergraduate medical students. J Am Geriatr Soc. 2010;58(10):1987-93.

10. Beer C, Watson N, Caputo L, Hird K, Flicker L. Students and teachers' preferences for undergraduate dementia education in Western Australia. Gerontol Geriatr Educ. 2011;32(3):273-90.

11. Bernard MA, MCAuley WJ, Belzer JA, Neal KS. An evaluation of a lowintensity intervention to introduce medical students to healthy older people. J Am Geriatr Soc. 2003;51(3):419-23.

12. Brand G, Osborne A, Carroll M, Carr SE, Etherton-Beer C. Do photographs, older adults' narratives and collaborative dialogue foster anticipatory reflection ("preflection") in medical students? BMC Med Educ. 2016;16(1):289.

13. Cheong SK, Wong TY, Koh GC. Attitudes towards the elderly among Singapore medical students. Ann Acad Med Singap. 2009;38(10):857-61.

14. Chua MP, Tan CH, Merchant R, Soiza RL. Attitudes of first-year medical students in Singapore towards older people and willingness to consider a career in geriatric medicine. Ann Acad Med Singap. 2008;37(11):947-51.

15. Diachun L, Van Bussel L, Hansen KT, Charise A, Rieder MJ. "But I see old people everywhere": dispelling the myth that eldercare is learned in nongeriatric clerkships. Acad Med. 2010;85(7):1221-8.

16. Duke P, Cohen D, Novack D. Using a geriatric mentoring narrative program to improve medical student attitudes towards the elderly. Educ Gerontol. 2009;35(10):857-66.

17. Eskildsen MA, Flacker J. A multimodal aging and dying course for firstyear medical students improves knowledge and attitudes. J Am Geriatr Soc. 2009;57(8):1492-7.

18. Fields SD, Jutagir R, Adelman RD, Tideiksarr R, Olson E. Geriatric education Part 1: efficacy of a mandatory clinical rotation fourth year medical students. J Am Geriatr Soc. 1992;40(9):964-9.

19. Gonzales E, Tan J, Morrow-Howell N. Assessment of the refined aging semantic differential: recommendations for enhancing validity. J Gerontol Soc Work. 2010;53(4):304-18.

20. Hall NK, Riesenberg LA, Stein LK, Biddle WB. Longitudinal effectiveness of a medical school geriatrics clerkship. Acad Med. 1997;72(10):S28-30.

21. Hughes NJ, Soiza RL, Chua M, Hoyle GE, MacDonald A, Primrose WR, et al. Medical student attitudes toward older people and willingness to consider a career in geriatric medicine. J Am Geriatr Soc. 2007;56(2):334-8.

22. Intrieri RC, Kelly JA, Brown MM, Castilla C. Improving medical students' attitudes twoard and skills with the elderly. Gerontol. 1993;33(3):373-8.

23. Koh GCH, Merchant RA, Lim WS, Amin Z. The knowledge-attitude dissociation in geriatric education: can it be overcome? Ann Acad Med Singap. 2012;41(9):383-9. 
24. Lorraine V, Allen S, Lockett A, Rutledge CM. Sensitizing students to functional limitations in the elderly: an aging simulation. Fam Med. 1998;30(1):15-8

25. Lu WH, Hoffman KG, Hosokawa MC, Gray MP, Zweig SC. First year medical students' knowledge, attitudes, and interest in geriatric medicine. Educ Gerontol. 2010;36:687-701.

26. Muangpaisan W, Intalapapron S, Assantachai P. Attitudes of medical students and residents toward care of the elderly. Educ Gerontol. 2008;34(5):400-6.

27. Nagoshi MH, Tanabe MKG, Sakai DH, Masaki KH, Kasuya RT, Blanchette PL. The impact of curricular changes on the geriatrics knowledge, attitudes and skills of medical students. Gerontol Geriatr Educ. 2008;28(3):47-58.

28. Pacala JT, Boult C, Bland C, O'Brien J. Aging game improves medical students'attitudes toward caring for elders. Gerontol Geriatr Educ 1995;15(4):45-57.

29. Roscoe LA, Schonwetter RS, Wallach PM. Advancing geriatrics education: evaluation of a new curricular initiative. Teach Learn Med. 2005:17(4):355-62.

30. Sahin S, Mandiracioglu A, Tekin N, Senuzun F, Akcicek F. Attitudes toward the elderly among the health care providers: reliability and validity of Turkish version of the UCLA Geriatrics Attitudes (UCLA-GA) scale. Arch Gerontol Geriatr. 2012;55(1):205-9.

31. Seaman K, Saunders R, Williams E, Harrup-Gregory J, Loffler H, Lake F. An examination of students' perceptions of their interprofessional placements in residential aged care. J Interprof Care. 2017;31(2):147-53.

32. Shue CK, McNeley K, Arnold L. Changing medical students' attitudes about older adults and future older patients. Acad Med. 2005;80(10):S6-9.

33. Stewart TJ, Eleazer GP, Boland R, Wieland GD. The middle of the road: results from the aging semantic differential with four cohorts of medical students. J Am Geriatr Soc. 2007;55(8):1275-80

34. Tam KL, Chandran K, Yu S, Nair S, Visvanathan R. Geriatric medicine course to senior undergraduate medical students improves attitude and selfperceived competency scores. Australas J Ageing. 2014;33(4):E6-11.

35. Ten Haken JD, Woolliscroft JO, Smith JB, Wolf FM, Calhoun JG. A longitudinal investigation of changes in medical students' attitudes toward the elderly. Teach Learn Med. 1995;7(1):18-22.

36. Varkey P, Chutka DS, Lesnick TG. The aging game: improving medical students' attitudes toward caring for the elderly. J Am Med Dir Assoc. 2006;7(4):224-9.

37. Watson N. e-ageing: development and evaluation of a flexible online geriatric medicine educational resource for diverse learners e-ageing: online education modules. Australas J Ageing. 2013;32(4):222-8.

38. Wilkinson TJ, Gower S, Sainsbury R. The earlier, the better: the effect of early community contact on the attitudes of medical students to older people. Med Educ. 2002;36:540-2.

39. Wilson R, Glamser FD. The impact of a gerontological intervention on osteopathic medical students. Educ Gerontol. 1982;8(4):373-80.

40. Zwahlen D, Herman CJ, Smithpeter MV, Mines J. Medical students' longitudinal and cross-sectional attitudes toward and knowledge of geriatrics at the University of New Mexico school of medicine. J Am Geriatr Soc. 2010:58:2049-50

41. Stagner R, Osgood CE. Impact of war on a nationalistic frame of reference: I. Changes in general approval and qualitative patterning of certain stereotypes. J Soc Psychol. 1946;24(2):187-215.
42. Osgood CE. The nature and measurement of meaning. Psychol Bull. 1952;49(3):197-237.

43. Rosencranz HA, McNevin TE. A factor analysis of attitudes toward the aged. Gerontologist. 1969;9(1):55-9.

44. Intrieri RC, Von Eye A, Kelly JA. The aging semantic differential: a confirmatory factor analysis. Gerontologist. 1995;35(5):616-21.

45. Kogan N. Beliefs, attitudes, and stereotypes about old people. A new look at some old issues. Res Aging. 1979;1(1):11-36.

46. Palmore EB. Attidudes toward the aged. What we know and need to know. Res Aging. 1982;4(3):333-48.

47. Verhagen T, van den Hoff B, Meents S. Toward a better use of the semantic differential in IS research: an integrative framework of suggested action. J Assoc Inf Syst. 2015;16(2):108-43.

48. Auken SV, Barry TE. An Assessment of the trait validity of cognitive age measures. J Consum Psychol. 1995;4(2):107-32

49. Underwood DG, Eklund SJ, Whisler S. A reexamination of the factor structure of the aging semantic differential using a generalized social object. Educ Gerontol. 1985:11(6):321-35.

50. Polizzi KG. Assessing attitudes toward the elderly: Polizzi's refined version of the aging semantic differential. Educ Gerontol. 2003;29(3):197-216.

51. Iwasaki M, Jones JA. Attitudes toward older adults: a reexamination of two major scales. Gerontol Geriatr Educ. 2008;29(2):139-57.

52. Reuben DB, Lee M, Davis JW Jr, Eslami MS, Osterweil DG, Melchiore $S$, et al. Development and validation of a geriatrics attitudes scale for primary care residents. J Am Geriatr Soc. 1998;46(11):1425-30.

53. Stewart T, Roberts E, Eleazer $P$, Boland R. Reliability and validity issues for two common measures of medical students' attitudes toward older adults. Educ Gerontol. 2006;32(6):409-21.

54. Fitzgerald JT, Wray LA, Halter JB, Williams BC, Supiano MA. Relating medical students' knowledge, attitudes, and experience to an interest in geriatric medicine. Gerontologist. 2003;43(6):849-55.

55. Kishimoto M, Nagoshi M, Williams S, Masaki KH, Blanchette PL. Knowledge and attitudes about geriatrics of medical students, internal medicine residents, and geriatric medicine fellows. J Am Geriatr Soc. 2005;53(1):99-102.

56. Maxwell AJ. Attitudes toward the geriatric patient among Family Practice residents. J Am Geriatr Soc. 1980;28(8):341-5.

57. Fraboni M, Saltstone R, Hughes S. The Fraboni Scale of Ageism (FSA): an attempt at a more precise measure of ageism. Can J Aging. 1990:9(1):56-66.

58. Rupp DE, Vodanovich SJ, Crede M. The multidimensional nature of ageism: construct validity and group differences. J Soc Psychol. 2005;145(3):335-62.

59. Leung S, Logiudice D, Schwarz J, Brand C. Hospital doctors' attitudes towards older people. Intern Med J. 2011;41(4):308-14.

60. Hollar D, Roberts J, Busby-Whitehead J. COCOA: a new validated instrument to assess medical students' attitudes towards older adults. Educ Gerontol. 2011;37(3):193-209.

61. Lin X, Bryant C, Boldero J. Measures for assessing student attitudes toward older people. Educ Gerontol. 2011;37(1):12-26.

\section{Submit your next manuscript to BioMed Central and we will help you at every step:}

- We accept pre-submission inquiries

- Our selector tool helps you to find the most relevant journal

- We provide round the clock customer support

- Convenient online submission

- Thorough peer review

- Inclusion in PubMed and all major indexing services

- Maximum visibility for your research

Submit your manuscript at www.biomedcentral com/submit 